\title{
Article
}

\section{Albumin Based lohexol Nanoparticles for Computed Tomography: An In Vivo Study}

Kale, Trupti, Bendale, Kiran, Singh, Kamalinder and Chaudhari, Pradip

Available at https://clok.uclan.ac.uk/25953/

Kale, Trupti, Bendale, Kiran, Singh, Kamalinder orcid iconORCID: 0000-00017325-0711 and Chaudhari, Pradip (2019) Albumin Based lohexol Nanoparticles for Computed Tomography: An In Vivo Study. Journal of Biomedical Nanotechnology, 15 (2). pp. 236-247. ISSN 1550-7033

It is advisable to refer to the publisher's version if you intend to cite from the work. http://dx.doi.org/10.1166/jbn.2019.2690

For more information about UCLan's research in this area go to http://www.uclan.ac.uk/researchgroups/ and search for <name of research Group>.

For information about Research generally at UCLan please go to http://www.uclan.ac.uk/research/

All outputs in CLoK are protected by Intellectual Property Rights law, including Copyright law. Copyright, IPR and Moral Rights for the works on this site are retained by the individual authors and/or other copyright owners. Terms and conditions for use of this material are defined in the policies page. 


\title{
Albumin Based lohexol Nanoparticles for Computed Tomography: An In Vivo Study
}

\author{
Trupti Kale ${ }^{2}$, Kiran Bendale ${ }^{1}$, Kamalinder K. Singh ${ }^{3 *}$, and Pradip Chaudhari ${ }^{1}$, * \\ ${ }^{1}$ Advanced Centre for Treatment Research and Education in Cancer, Tata Memorial Centre, Navi Mumbai 410210, India \\ ${ }^{2}$ C. U. Shah College of Pharmacy, SNDT Women's University, Santacruz (W), Mumbai 400049, India \\ ${ }^{3}$ School of Pharmacy and Biomedical Sciences, University of Central Lancashire, Preston, PR1 2HE, United Kingdom
}

\begin{abstract}
Iohexol is a commonly used second generation non-ionic iodinated contrast agent with a multitude of advantages such as low osmolarity and competent intravenous countenance having minimum adverse reactions. Our study anticipated to improve the efficacy of lohexol as a contrast enhancing agent for Computed Tomography, by envisaging bio-compatible albumin based lohexol nanoparticles. This nanoparticulate system was developed primarily to enhance the anatomic imaging while increasing its residence time in the blood pool. Towards this goal, we developed lohexol albumin nanoparticles using glutaraldehyde as a cross linking agent, and Polyethylene glyocol lohexol albumin nanoparticles by physical adsorption to ameliorate its circulation time. These formulations were studied in comparison to the clinically available Iopamidol $^{\mathrm{TM}}$. Both lohexol albumin nanoparticles and Polyethylene glyocol lohexol albumin nanoparticles were characterized for its size, physicochemical properties and entrapment efficiency. lohexol albumin nanoparticles showed a size range of $254 \pm 5 \mathrm{~nm}$ and post surface modification the size of Polyethylene glyocol lohexol albumin nanoparticles was found to be $283 \pm 7 \mathrm{~nm}$ in diameter, with and entrapment efficiency lohexol as of $85 \%$. Further, In vivo computed tomography imaging in New Zealand white rabbits for the developed formulations manifested an enhancement in the anatomical structures of heart, liver and kidneys along with an increased residence time in the blood pool of $3 \mathrm{~h}$ in contrast to Iopamidol $^{\mathrm{TM}}$. Our study interprets that Polyethylene glyocol lohexol albumin nanoparticles have prolonged residence time producing much greater conspicuity of anatomic features and warrants further detailed study of the formulation in disease models.
\end{abstract}

KEYWORDS: Nanoparticle, Contrast Agent, Computed Tomography, Iohexol, Albumin, Rabbit.

\section{INTRODUCTION}

Computed tomography (CT) is one of the extensively used imaging modalities for pre-clinical and clinical investigations of a wide array of medical conditions. X-rays, which are a source of ionizing radiation made use in CT enables the visualization and distinction of tissues inside organs. Further, this imaging technique is proficient in acquiring three dimensional images of soft tissues including blood vessels and brain. Contrast agents are imperative in radioimaging and radio-therapeutics. Remarkable furtherance in augmenting the composition of these contrast agents have made them invulnerable. A study reviewed that, iodinated contrast agents which are clinically approved and having low osmolarity are assimilated rapidly by soft tissues,

\footnotetext{
*Authors to whom correspondence should be

addressed. Email: pchaudhari@actrec.gov.in;

ksingh1@uclan.ac.uk

Received: 21 September 2018

Accepted: 25 September 2018

J. Biomed. Nanotechnol. 2019, Vol. 15, No. xx
}

bones and blood vessels enabling the visualization of the anatomical structures with utmost coherence. ${ }^{1,2}$ Nonetheless, the risk kindred with conventional contrast agents have not been nullified. However, due to the snag of rapid renal clearance of conventional iodinated contrast agents, discrepancy in the levels of contrast would vary during the course of the study. In addition, X-ray attenuation of iodine is not efficacious for clinical CT that uses high-energy X-rays. Further, rapid renal clearance, is associated with significant adverse consequences such as anaphylactic reactions causing urticaria, laryngeal edema, bronchospasm and non-anaphylactic reactions including pulmonary edema, cardiac arrhythmias, nausea, seizures and renal failure which are sometimes fatal in nature. ${ }^{3}$ This has generated interest in engineering novel nano sized contrast agent formulations to subdue the shortcomings of the conventional contrast agents, simultaneously ameliorating the radiograph. 
Enormous amount of formulations are augmented as a substitute for CT contrast like gadolinium chelates and clusters of tungsten. ${ }^{4,5}$ Integration of nano-composite contrast formulations into clinical mainstreams will revolutionize the radio-diagnostic techniques. Nano-medicine has metamorphosed the area of diagnosis and therapy. The therapeutic applications of nano-formulations include targeted drug delivery, various imaging modalities such as PET, MRI, fluorescent and photoacoustics, gene delivery, thermal ablation and many more. ${ }^{6-8}$ However, implementation of nanotechnology in radio diagnostic techniques to develop contrast agent for CT is now being developed. ${ }^{9}$ A variety of materials are used to develop nanocomposite contrast agents such as bromine, platinum, bismuth, iodine. ${ }^{10-13}$ Such core are usually modified using lipids, proteins, polymers, in order to enhance its solubility, biocompatibility and its residence time in blood pool. ${ }^{14}$ The reason to select nanoparticle for contrast agent study is because clinically approved CT contrast agents are small molecules and are therefore swiftly excreted via the kidneys. Nanoparticles, on the other hand, can be synthesized to be larger than the renal fenestrae and therefore remain in the bloodstream. They can carry a high load of contrast agent compared with small molecules besides coating material properties also dominates blood circulation time. The long circulating contrast agents have ability to visualize the blood vessels for longer duration in case of imageguided surgeries. Biocompatible albumin nanoparticles has an added advantage for individuals having contraindication for conventional iodinated agents due to renal insufficiency and allergic reactions. ${ }^{15}$ The formulation in the present study is biocompatible and cost effective having potential for further clinical application.

Liposomal CT contrast moieties have been widely studied for pre-clinical applications using water-soluble iodinated contrast agents. ${ }^{16,17}$ A study showed that, lipid based agents were rapidly cleared by the reticuloendothelial system (RES), and thus were used mainly to detect solid tumors of the liver or spleen. However, these are usually surface modified with Polyethylene Glycol (PEG) to increase their circulation time. ${ }^{18}$ In contrast, liposome nano-composites of contrast agents for CT have some limitations, including low encapsulation efficiency, fast burst release of drugs and poor storage stability. ${ }^{19}$ Nano formulated contrast enhancing agents have the ability to with stand physiological stress along with improved biological stability; prolong half-life $\left(t_{1 / 2}\right)$ in the blood pool and longterm storage. All these advantages make them appealing as theragnostic agents over conventional ones. ${ }^{20-22}$ Nanoparticulate contrast system would be useful to reduce dose of intravenous administration, along with appreciable sensitivity and specificity of imaging modalities. This has led to the development of several iodine based nanoformulations for higher $t_{1 / 2}$ and in lesion signal enhancement without multiple administrations of contrast. ${ }^{23-25}$
Protein based nanoparticle drug delivery system are studied to have diminished toxicity, and are non-antigenic in vivo. Furthermore, albumin nanoparticles are nonimmunogenic, biocompatible and biodegradable, which is easy to purify and water soluble allowing easy intravenous administration. ${ }^{26}$ Albumin nanoparticles are cleared via hepatobiliary or renal route, hence complete clearance is achievable in few hours post administration. Besides it can be safely used in subjects with compromised renal or hepatic function. Albumin can been modified to create novel nanostructures for drug delivery applications. Modification with Polyethylene Glycol (PEG) reduces opsonization by reticulo endothelial system, while prolonging its circulation in the blood pool. ${ }^{27-29}$ Iohexol is a commonly used time tested second-generation contrast agent, which has a proficient residence time for visualization of anatomic structures.

This study was aimed to develop and evaluate albumin nanocarrier system of iohexol to provide high contrast agent loading for computed tomography imaging, to prolong circulation of contrast agent in the blood and to improve organ vascularization with minimal side effects. We developed Iohexol Albumin Nanoparticles (IAP) and also surfaced modified it by PEGylation (P-IAP) and evaluated in pre-clinical setup.

\section{MATERIALS AND METHOD Formulation of Albumin Based lohexol Nanoparticles}

Iohexol nanoparticles were prepared by coacervation technique, followed by cross linking with glutaraldehyde. Iohexol (Histodenz, Sigma Aldrich@, Biotechnology LP and Sigma-Aldrich Co., USA) at a concentration of $350 \mathrm{mg}$ of iodine per milliliter was solubilized using $2 \% \mathrm{v} / \mathrm{v}$ of albumin solution. IAP were prepared by method as described earlier. ${ }^{30}$ Briefly, Iohexol was incubated in Human Serum Albumin (HSA) solution (Life-line pharma Pvt Ltd., Colombo, Shri Lanka) for $10 \mathrm{~min}$, and the $\mathrm{pH}$ was adjusted to alkaline side using $1 \% \mathrm{NaOH}$ (Merk, India). Ethanol (Sterling chemicals and Alcohols Pvt. Ltd. Pune, India) was added as a desolvating agent at the rate of $1 \mathrm{~mL} /$ min under continuous stirring for $10 \mathrm{~min}$. Further, glutaraldehyde (SD Fine chemicals Pvt. Ltd., Mumbai, India) was added slowly to induce particle cross linking and allowed to stir for $3.5 \mathrm{~h}$. Twelve batches from PN1 to PN12 (four of each glutaraldehyde concentration) were studied for the effect of glutaraldehyde concen-tration at $20,25,30 \mu \mathrm{L} / \mathrm{mL}$ and stirring time at $1,2,3$ and $3.5 \mathrm{~h}$ on particle size and polydispersity index (PI) using $3^{2}$ factorial design and response surface methodology.

\section{PEGylation, Lyophilization and Sterilization of IAP}

Optimized albumin nanoparticle batch PN8 with particle size $254 \mathrm{~nm}$ and P.I. of 0.20 was subjected to surface 
modification with PEG 1500, PEG 4000 and PEG 6000 by physical adsorption, at 3 concentration levels i.e., 0.4 , 0,8 and $1.2 \% \mathrm{w} / \mathrm{v}$ by incubation for $3 \mathrm{~h}$. PEG 4000 was chosen for further study and added to the previously optimized IAP and its effect on PI and particle size was further studied. Lyophilization of both IAP and P-IAP was carried out using Martin Christ Epsilon 2, 4 LSC freeze dryer. Various cryoprotectants like sucrose, mannitol, trehalose were screened at different concentrations. But 20\% Mannitol was selected as a suitable cryoprotectant after screening for different physical parameters. The system was evacuated using $0.05 \mathrm{~m}$. bar vacuum and freezing was done at $-50{ }^{\circ} \mathrm{C}$ for $5 \mathrm{~h}$ followed by primary drying at -50 ${ }^{\circ} \mathrm{C}$ to $-20{ }^{\circ} \mathrm{C}$ for $20 \mathrm{~h}$ and sec-ondary drying at 10 ${ }^{\circ} \mathrm{C}$ to $30{ }^{\circ} \mathrm{C}$ for $14 \mathrm{~h}$. Lyophilized NPs were collected and characterized further. Lyophilized formulations (Ly IAP and Ly P-IAP) filled in amber colour vials were packed in thermacol box along with coolent. Sterilization was performed by radiating the samples using $25 \mathrm{kGy}$ of gamma radiation and sterilized formulations were prepared (S IAP, and $\mathrm{S}$ P-IAP). Doses were monitored with specific dosimeters during the entire process of sterilization. Optimized IAP, P-IAP, Ly IAP, Ly P-IAP, S IAP, and S PIAP batches were collected and characterized for further studies.

\section{Characterization of Formulation}

Preliminary characterization of IAP and P-IAP was carried out to screen parameters such as visual appearance, $\mathrm{pH}$, particle size and polydispersity index (PDI), transmission electron microscopy (TEM), Confocal microscopy. PDI was determined using N5 Beckmann sub-micron particle size analyzer. These particles were further characterized by transmission electron microscopy (TEM) to determine the size and coating around IAP. The samples for TEM were prepared by sonicating the samples in Milli $Q$ at a concentration of $(10 \mu \mathrm{g} / \mathrm{mL})$. coated copper grids and allowed to settle for 3 to $5 \mathrm{~min}$ then these grids were further dried under UV lamp and stained with $1 \%$ uranyl acetate solution. Dried sample were analyzed using transmission electron microscope (Philips CM, operating voltage 20 to $200 \mathrm{Kv}$ model with resolution $2.4 \AA$ ) and area of interest was scanned at higher magnification $(80,000 \times-$ $200,000 \times$ ) to confirm the surface modification and shape of NPs. Confocal microscopy of the selected nanoparticle was done using confocal microscope Bio Rad MRC 1024 with 2 microscopes as Nikon E60 and dual line Argon ion laws to confirm the surface modification and shape of nanoparticles.

\section{Stability Assessment of IAP and P-IAP}

It was studied at various conditions viz. refrigeration $25 \pm 2 \mathrm{C} / 60 \pm 5 \% \mathrm{RH}, 30 \pm 2 \mathrm{C} / 65 \pm 5 \% \mathrm{RH}, 40 \pm 2 \mathrm{C} / 75 \pm$ $5 \% \mathrm{RH}$ where the formulations were analyzed for appearance, $\mathrm{pH}$, particle size, polydispersity index, syringeability and injectability. The iodine concentration of albumin nanoparticle formulation was determined by absorption of UV light at $254 \mathrm{~nm}$ wavelength with a Jasco UV 630 Spectrophotometer system at predetermined time intervals of 0 , $30,60,90$ days.

\section{Determination of Entrapment Efficiency}

Entrapment efficiency of Iohexol in IAP and P-IAP was determined by RP-HPLC (Jasco PU 2089 pump, Jasco UV 2070 plus detector). A standard curve with known concentration of Iohexol was developed so as to quantify the amount of iohexol in the developed formulation. Extinction coefficient of Iohexol was calculated as $26,600 \mathrm{M}^{-1} \mathrm{~cm}^{-1}$. A range of Iohexol working solution $(2,4,6,8 \mu \mathrm{g} / \mathrm{mL})$ was prepared from $1 \mathrm{mg} / \mathrm{mL}$ stock solution. Iohexol was quantified at $254 \mathrm{~nm}$, using Technokroma C-18 column $(25 \mathrm{~cm} \times 4.5 \mathrm{~mm}, 0.5 \mu \mathrm{m})$ with acetonirile and water $(99: 01 \mathrm{v} / \mathrm{v})$ at a flow rate of $0.5 \mathrm{~mL} / \mathrm{min}$. Further, entrapped iohexol in IAP and P-IAP dispersion was extracted by ultracentrifugation at 9000 rpm for $10 \mathrm{~min}$. The pellet obtained was digested with $0.5 \%$ trypsin solution. This was further centrifuged at 9000 rpm for $10 \mathrm{~min}$ and the supernatant obtained was filtered (filter having a pore size of $0.22 \mu$ ). This was diluted with mobile phase and quantified by RP-HPLC. Percent entrapment of iohexol in NPs was determined using formula:

$$
\text { Entrapment Efficiency }=\text { Total drug }- \text { Free drug }
$$$$
/ \text { Total drug } \times 100
$$

\section{In Vitro Release of lohexol}

In vitro release of iohexol was studied by dialysis bag method. Dialysis bag (MWCO 12-14 Kda, Sigma Aldrich) containing $2 \mathrm{~mL}$ of IAP/P-IAP was placed in a conical flask containing $200 \mathrm{~mL}$ of dissolution media (phosphate buffered saline (PBS), $\mathrm{pH}-7.4$ ). These flasks were kept in shaker water bath maintained at $37{ }^{\circ} \mathrm{C}$ under constant agitation of 100 vibrations per $\min .5 \mathrm{~mL}$ sample was withdrawn at specific time intervals for a period of $4 \mathrm{~h}$ and replaced with same volume of fresh medium. The released contrast agent was quantified using a UV spectrophotometer (Jasco UV630) at a wavelength of $254 \mathrm{~nm}$. A graph of $\%$ Iohexol release versus time was plotted. Contrast release was studied using different release study models such as Zero order, First order release and Higuchi model.

\section{Animals}

Animal experiments were performed with prior approval from the Institutional Animal Ethics Committee (IAEC/042010). All the animal studies were carried out under the guidelines complied by CPCSEA (Committee for the Purpose of Control and Supervision of Experiments on Animals). New Zealand white rabbits were housed and maintained according to ARRP guidelines (http://www.animalethics.org.au/_data/assets/pdf_file/0013/ 222511/housing-rabbits-scientific-institutions.pdf). Food and 
water to the animals were supplied ad libitum. Animals were fasted for $3 \mathrm{~h}$ before injecting the contrast. Dosing of the animals was done as follows:

Group 1: Animals were injected with $3.170 \mathrm{~mL} / \mathrm{kg} \cdot \mathrm{b} . \mathrm{wt}$ of IAP

Group 2: Animals were injected with $3.170 \mathrm{~mL} / \mathrm{kg} \cdot \mathrm{b} . \mathrm{wt}$ of P-IAP

Group 3: Animals were injected with $1 \mathrm{~mL} / \mathrm{kg} \cdot \mathrm{b} . \mathrm{wt}$ of Iopamidol $^{\mathrm{TM}}(370 \mathrm{mg} / \mathrm{mL})$.

Prior to intravenous administration of the contrast, all the animals included in the study were anesthetized with an intramuscular (IM) injection of ketamine and xyalazine mixture $(35 \mathrm{mg} / \mathrm{kg}$ ·b.wt. ketamine and $5 \mathrm{mg} / \mathrm{kg}$. b.wt. xylazine) during each imaging session. Rabbits were placed on patient bed in prone position. Iohexol nanoparticulate formulations (Dose for rabbit = Absolute human dose $\times 0.07)$ and standard contrast agent Iopamidol $^{\mathrm{TM}}$ (1 $\mathrm{mL} / \mathrm{kg}$ body weight) was administered as a slow bolus via marginal ear vein. ${ }^{31}$

Whole body CT scan images were acquired throughout the course of study using four slice multi-detector row CT scanner (Sensation 4 CT, Siemens, Germany) operated at $80 \mathrm{kV}$ and $165 \mathrm{~mA} / \mathrm{s}$, with a reconstruction interval of $3 \mathrm{~mm}$. A pre and post contrast scan images of rabbit were acquired. Scan was performed at different time points such as $0,5,15,30,60$ and 180 min following injection of contrast formulation. Projection images were used to reconstruct tomograms with Syngo software (Siemens AG, Germany) using Kernal B 30 s medium smooth and FOV of $214 \mathrm{~mm}$ keeping slice width of $3 \mathrm{~mm}$ having $2.5 \mathrm{~mm}$ collimation. Contrast formulations were studied in each rabbit with flush out period of 2 weeks between injections of each formulation. Mean attenuation (in Hounsfield unit) was determined using Imalytics 3.0 (Philips Corporate Technologies, Germany) translational imaging software in axial plane at different region of interest like aorta, heart, kidney (medulla and cortex) and liver to note the clearance of contrast agent at each time point in each of the above region. The mean difference in attenuation post injection and pre-injection of the contrast agent defined as relative enhancement, was measured and results were plotted as time-attenuation curves.

\section{RESULTS}

\section{Solubility Study}

$1000 \mathrm{mg}$ of contrast agent was solubilized in $1 \mathrm{~mL}$ of $1 \%$ HSA solution with proper viscosity which is an adept criteria for any contrast agent. Hence 1\% HSA solution was found to be a good carrier for Iohexol nanoparticles with good entrapment efficiency.

\section{Optimization of Albumin Nanoparticles}

Effect of glutaraldehyde concentration at three levels such as $20,25,30 \mu \mathrm{l} / \mathrm{mL}$ was studied using $3^{2}$ factorial design. Batches with glutaraldehyde concentration of 20, 25 and

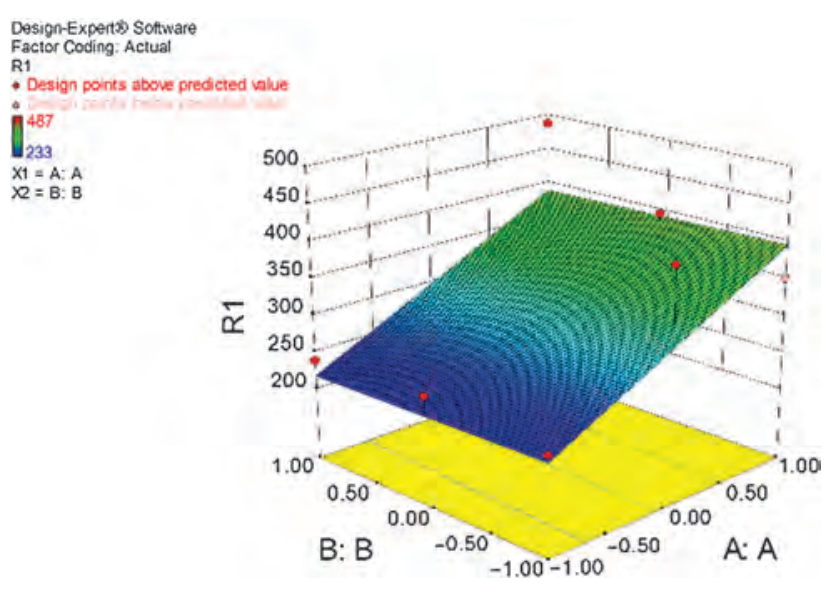

Figure 1. Effect of glutaraldehyde concentration and stirring time on particle size of different iohexol nanoparticle batches.

$30 \mu \mathrm{l} / \mathrm{mL}$ at the end of $3.5 \mathrm{~h}$ resulted in particle size of $238 \mathrm{~nm}, 254 \mathrm{~nm}, 450 \mathrm{~nm}$ and P.I. of $0.30,0.20,0.16$ respectively. From above results it could be concluded that glutaraldehyde concentration of $25 \mu \mathrm{l} / \mathrm{mL}$ was well within the acceptable range of stability, dispensability and sufficient to produce rigid nanoparticles with narrow particle size distribution (Figs. 1 and 2).

The effect of stirring time on particle size and P.I. was optimized using response surface method. Stirring for $3.5 \mathrm{~h}$ resulted in nanoparticles which were stable, hard and formed pellets after centrifugation which was indication of nanoparticle formation (Fig. 3).

\section{PEGylation of Albumin Nanoparticles}

PEG 4000 at concentration of $0.8 \%$ showed increase in particle size from 254 to $283 \mathrm{~nm}$ and lowered the P.I. from 0.20 to 0.14 indicating the surface modification or surface coating. Effect of different PEGs and their concentration on PI and particle size is shown in Figure 4.

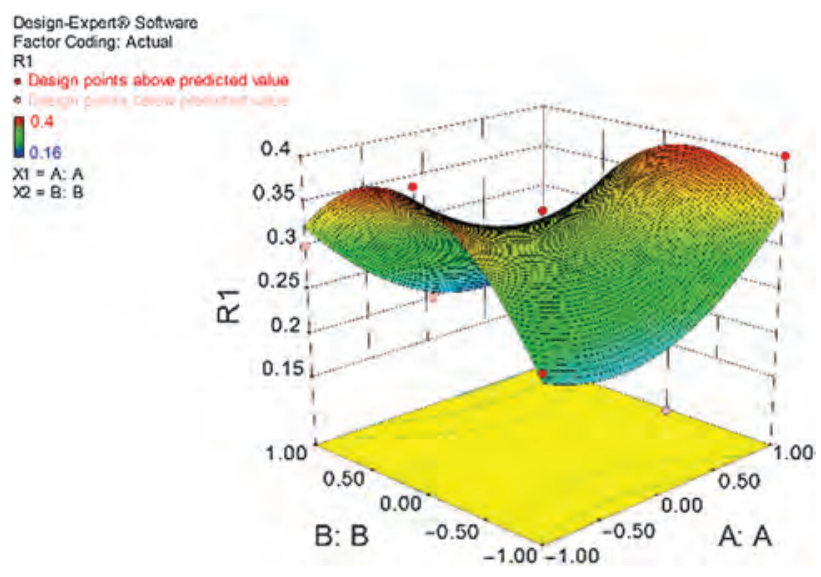

Figure 2. Effect of glutaraldehyde concentration and stirring time on polydispersity index of different iohexol nanoparticle batches. 


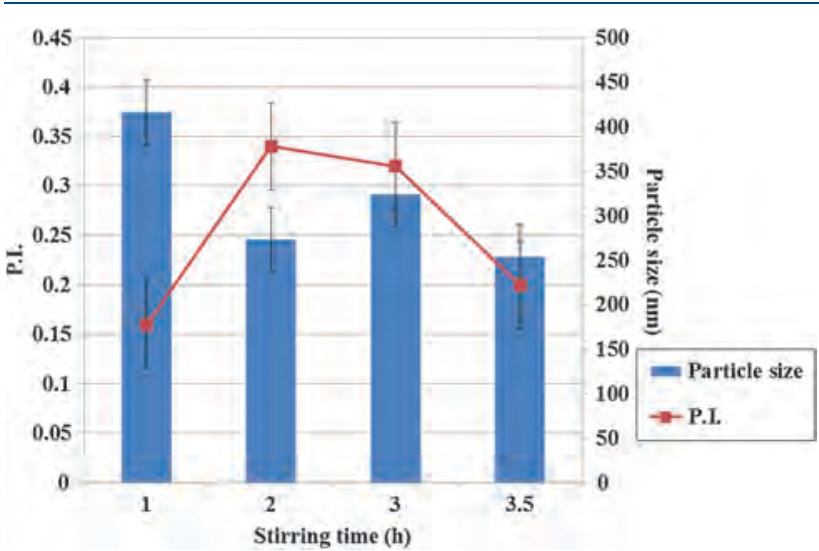

Figure 3. Effect of stirring time on iohexol nanoparticle batch PN 8 on particle size and polydispersity index.

\section{Characterization and Entrapment Efficiency of IAP and P-IAP}

Synthesized IAP and P-IAP appeared to be pale yellow in colour and odourless with no signs of instability till $24 \mathrm{~h}$. The mean particle size of IAP and P-IAP was found to be $254 \pm 5 \mathrm{~nm}$ and $283 \pm 7 \mathrm{~nm}$ respectively, with a narrow particle size distribution. P.I. takes into account the refractive index of the solvent angle of measurement and also variance of distribution. The P.I. of IAP was found to be 0.20 and in case of P-IAP, the P.I. was lowered from 0.20 to 0.14 . This shift in P.I. indicates surface modification. PH was maintained at 6.5 to 7.5 . Further, both IAP and P-IAP showed $92 \%$ (w/v) per cent content of iohexol, $85 \%$ entrapment efficiency with excellent syringebility and injectablity. TEM and confocal microscopy images of IAP and P-IAP confirmed the spherical shape and narrow size distribution of the particles. (Figs. 5(a,b) and $6(\mathrm{a}, \mathrm{b}))$ In IAP and P-IAP, particles were in range of $125 \mathrm{~nm}$ to $290 \mathrm{~nm}$ and $189 \mathrm{~nm}$ to $300 \mathrm{~nm}$ respectively and

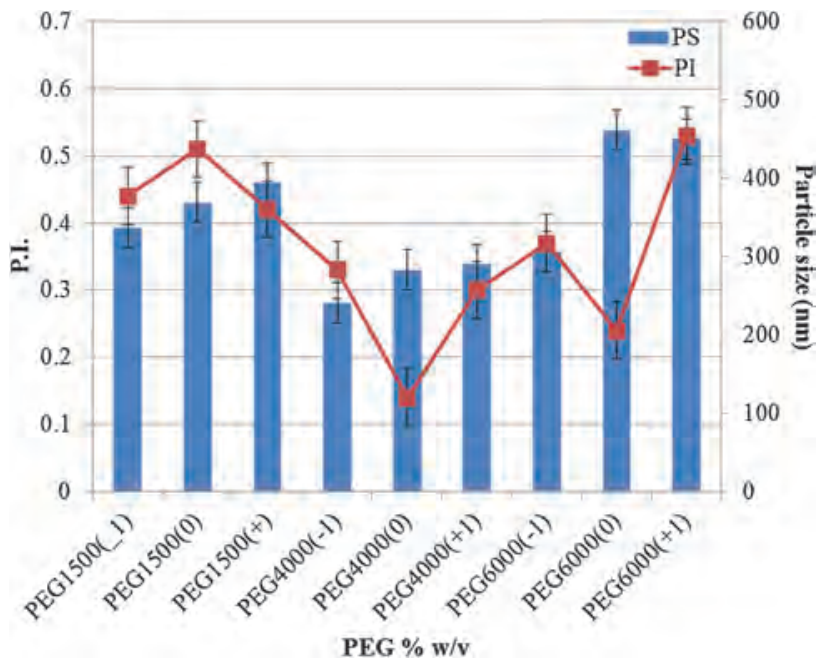

Figure 4. Effect of concentration of PEGs on particle size and polydispersity index of IAP. there was no significant difference in appearance of both formulation.

\section{Characterization of Lyophilized and Sterilized Nanoparticle Formulations}

Both Lyophilized nanoparticles were found to be easily redispersible in distilled water. The mean particle size of Ly IAP and Ly P-IAP was found to be $321 \pm 5 \mathrm{~nm}$ and $327 \pm 7 \mathrm{~nm}$ respectively which shows that there was a drastic increase in particle size after lyophilization. P.I of lyophilized IAP and P-IAP was found to be 0.09 and 0.36 respectively, indicating a monomodal distribution of dispersed system after lyophilization. However, P.I. lower than 0.1 might be associated with a high homogeneity in particle population. Confocal microscopy images of Ly IAP and Ly P-IAP confirmed the spherical shape and narrow size distribution of the particles. (Figs. 6(c,d)). There was no significant change was observed in other parameters. Also there was no significant difference found in all the parameters after sterilization.

\section{In Vitro Release of lohexol}

Both IAP and P-IAP showed first order release followed by Higuchi release pattern $\left(R^{2}=0.9860\right.$ and 0.9443 respectively, indicating matrix dependent release) (Fig. 7). IAP showed $>30 \%$ release at the end of $1 \mathrm{~h}$ and $>95 \%$ release at the end of $4 \mathrm{~h}$. However, P-IAP showed $>50 \%$ release at the end of $1 \mathrm{~h}$ and entire release of contrast till $4 \mathrm{~h}$. (Fig. 8) $T_{50 \%}$ of IAP and P-IAP was found to be $52 \mathrm{~min}$ and $50 \mathrm{~min}$ respectively. According to the release pattern, PEGylation (done by physical adsorption) of IAP did not cause major variation in the release profile of the contrast agent. There was no significant variation in release pattern of after lyophilization or sterilization (Fig. 9).

\section{Stability Results}

Both the nanoparticles showed no change in colour and $\mathrm{pH}$ was almost constant between 6.5 to 7.5. IAP were stable at $25 \pm 2{ }^{\circ} \mathrm{C} / 60 \pm 5 \% \mathrm{RH}$ but there was high increase in particle size and decrease in iohexol content over the three months of testing period. P-IAP formulation was stable at $25 \pm 2{ }^{\circ} \mathrm{C} / 60 \pm 5 \% \mathrm{RH}$ as well as $30 \pm 2{ }^{\circ} \mathrm{C} / 60 \pm 5 \% \mathrm{RH}$ with good syringebility. There was slight increase in PI up to 0.49 and decrease in iohexol content till the end of three months. Effect of temperature on particle size and polydispersity index of IAP and P-IAP at the end of three months is shown by graph in Figure 10.

\section{In Vivo Blood Pool Imaging}

In vivo $\mathrm{CT}$ imaging of heart and aorta showed that IAP and P-IAP provided significant visual contrast enhancement of the intravascular space up to three hours (Fig. 11). In contrast, Iopamidol administration showed least contrast in aorta up to 3 hours and most of the contrast was found in the bladder after $1 \mathrm{~h}$, which indicates early renal clearance. 


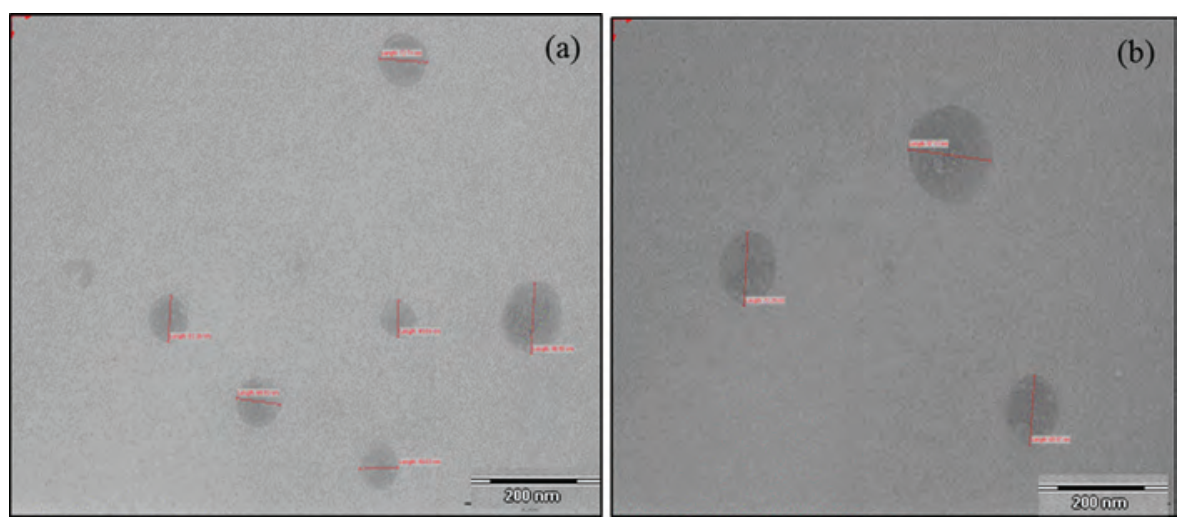

Figure 5. TEM images of (a) IAP and (b) P-IAP.

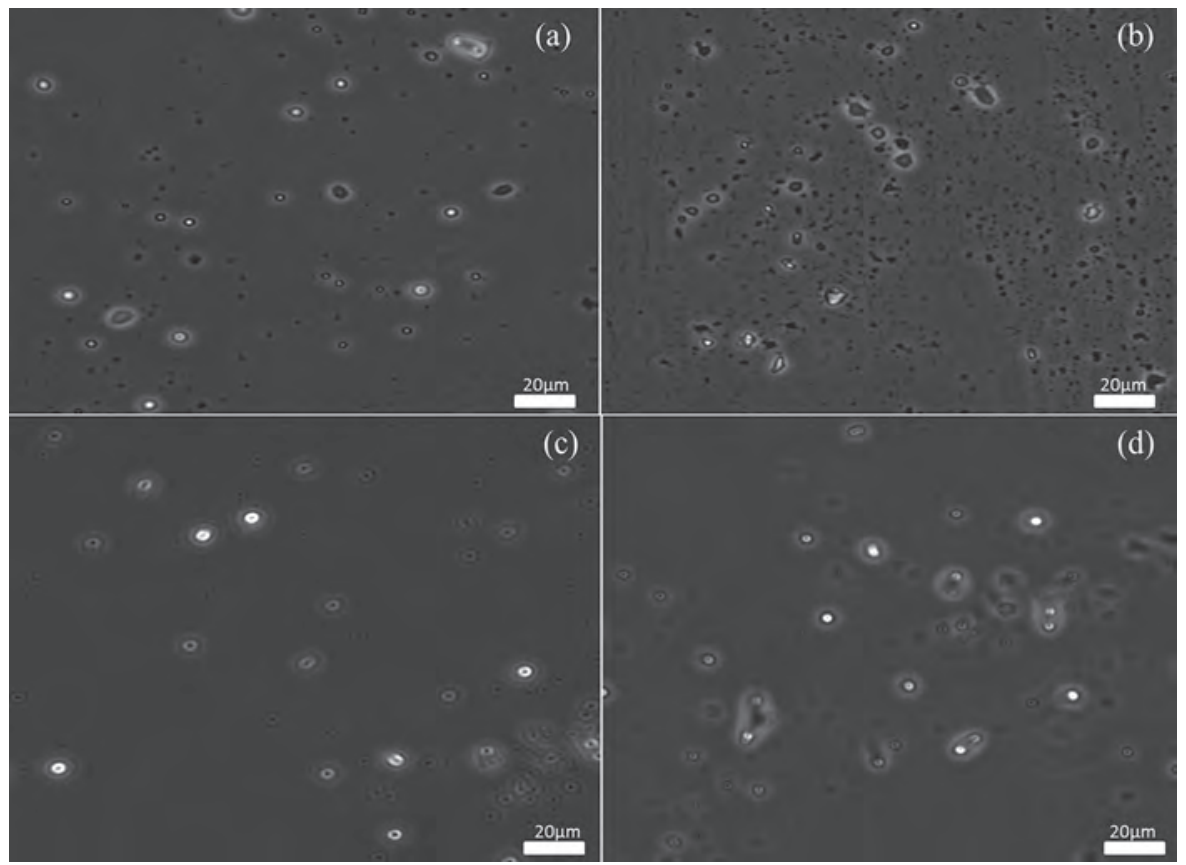

Figure 6. Confocal microscopy images of (a) IAP (b) P-IAP (c) Ly IAP and (d) Ly P-IAP.

No abnormal physiological changes were observed during imaging studies. Further, no extravasation of iohexol was observed at the time of injection or post injection. P-IAP also showed enhancement of kidney cortex up to 3 hours after injection of contrast material and transient increased attenuation in the medulla of kidney indicating early clearance (Fig. 12). Average attenuation of P-IAP $3 \mathrm{~h}$ post injection was 73.3, 96.1, 86.8 HU in heart, aorta and renal
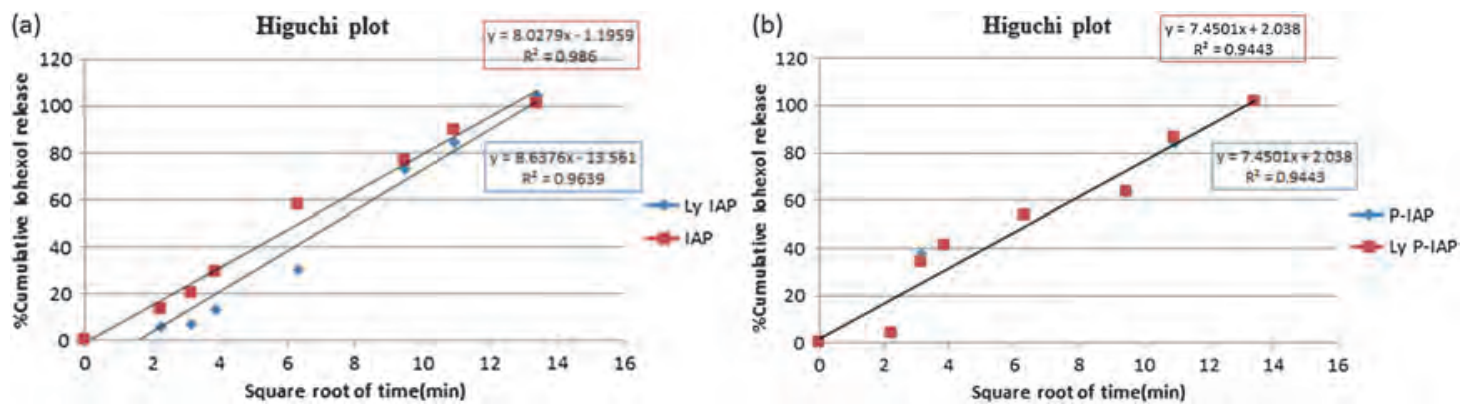

Figure 7. Graph of cumulative lohexol release versus square root of time between (a) IAP and Ly IAP; (b) P-IAP and Ly P-IAP. 


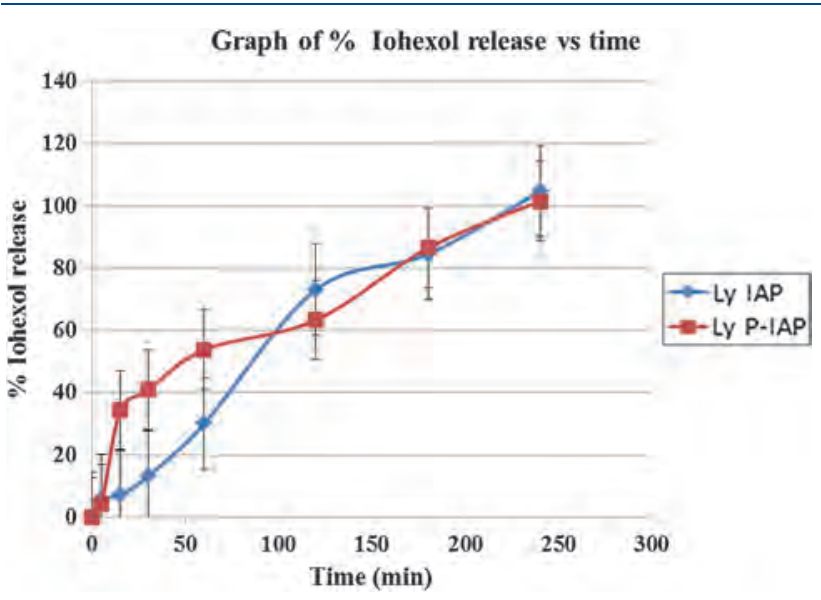

Figure 8. Graph of \% lohexol release versus time of Ly IAP and Ly P-IAP.

cortex respectively. Intensity of contrast in liver was found to be relatively constant till $3 \mathrm{~h}$. Prolonged enhancement achieved in the blood pool after administration of IAP and P-P-IAP demonstrates that albumin carriers are able to circulate and reside in the blood while retaining the coencapsulated small molecular weight agents like iohexol (Figs. 13, 14).

\section{DISCUSSION}

Assorted forms of contrast enhancing agents have been used in radio diagnostic techniques, to ameliorate medical imaging. Intravascular contrast agents are used in CT to culminate the blood vessels and intensify the tissue structures of various organs such as brain, spine, kidney and liver. However, in comparison to other pharmaceutical compounds, these contrast media are not entirely devoid of risk in systemic circulation. Limitations in the administration of contrast media could vary from minor physiological disturbances to alarming systemic imbalance. Some of the risk factors include allergy, asthma, ${ }^{32,33}$ renal insufficiency and contrast induced nephrotoxicity. ${ }^{34}$ Contrast induced nephropathy or post contrast acute kidney injury is a condition which generally occur $48 \mathrm{~h}$ post-administration of the contrast media, ${ }^{35,36}$ where the impairment in renal function results in an increased baseline level of creatinine in serum.

Iohexol is one of the second generation contrast media clinically used for CT, with high water solubility and low osmolality have comparatively low risk of adverse effect. ${ }^{37}$ However, intravascular administration of such iodinated contrast media leads to dilution in systemic circulation and rapid renal elimination without any significant metabolism. The half-life $\left(t_{1 / 2}\right)$ of such conventional contrast agent is reported to be 30-60 min in subjects with normal renal function. ${ }^{3}$ To combat the pitfalls of the conventional nonionic iodinated contrast agents, we engineered albumin based iohexol nanoparticles, in view of decreasing renal impairment as it bypasses renal clearance due to larger size and cleared by hepatic route after opsonization by
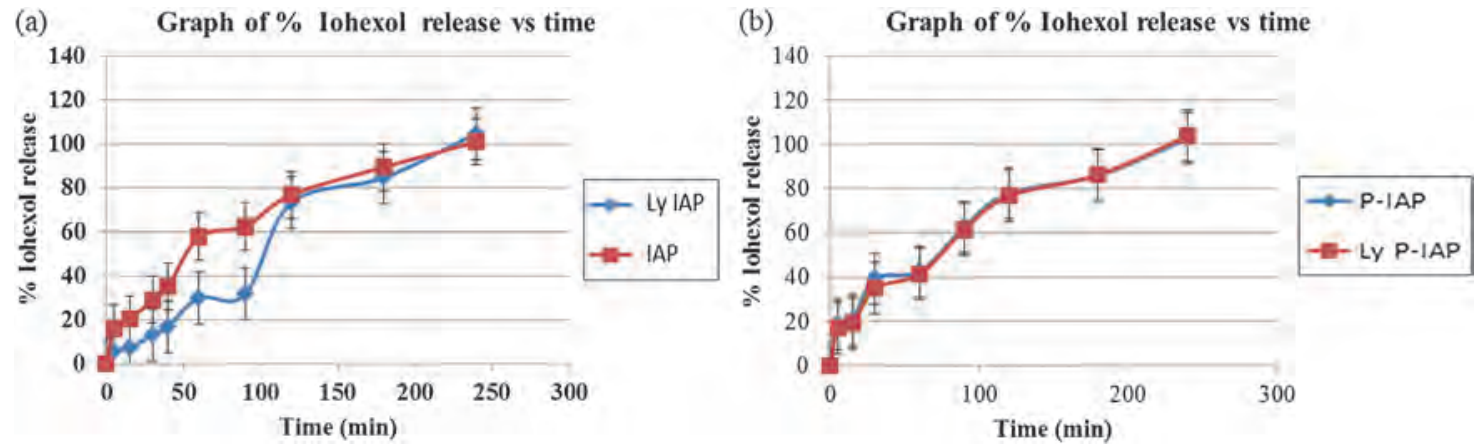

Figure 9. Graph of \% lohexol release versus time between (a) Ly IAP and IAP (b) P-IAP and Ly P-IAP.
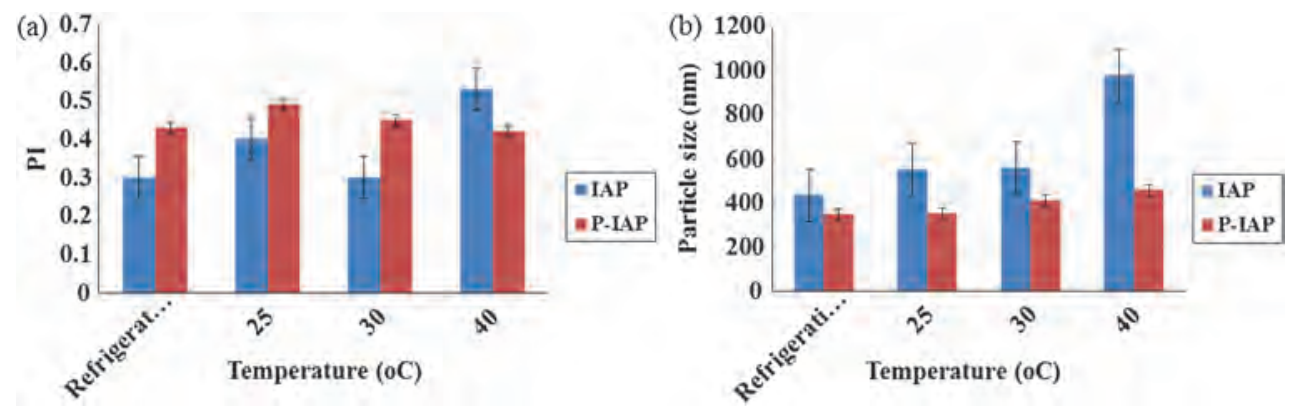

Figure 10. Graph showing effect temperature on (a) polydispersity index and (b) particle size of IAP and P-IAP. 


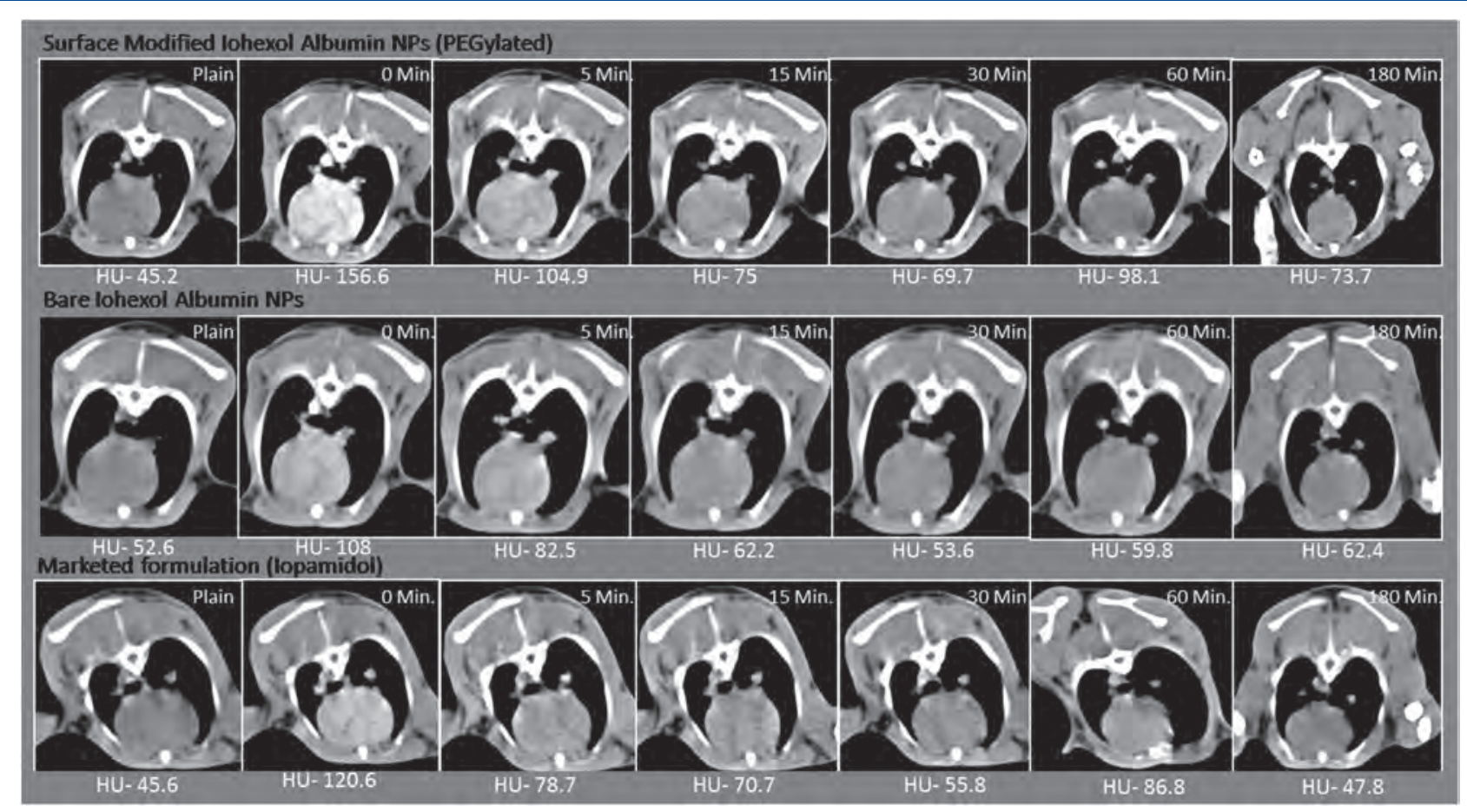

Figure 11. Representative computed tomographic axial images of rabbit demonstrating contrast visualization and variation in $\mathrm{HU}$ values of of heart and aorta acquired at various time points such as precontrast, $0,5,15,30,60$ and 180 minutes after injection of three different contrast agent formulations.

RES system and also increasing the half-life $\left(t_{1 / 2}\right)$ of the contrast media in the blood pool.

Molecular imaging being an emerging area in the field of radiology, diagnosing the molecular markers prior to the onset of biological symptoms which appears earlier in the clinical conditions plays a vital role in early and efficacious treatment of the medical condition. CT is the most convenient set up used for diagnosis clinically. Advancement in the field of nanomedicine has focused on developing bio-compatible nanoparticles to be employed as blood pool CT contrast agents, passive or active targeting agents. ${ }^{38}$ Owing to the growing community of renally impaired patients and those sensitive to iodine, micelle and liposome based contrast enhancing agents have been

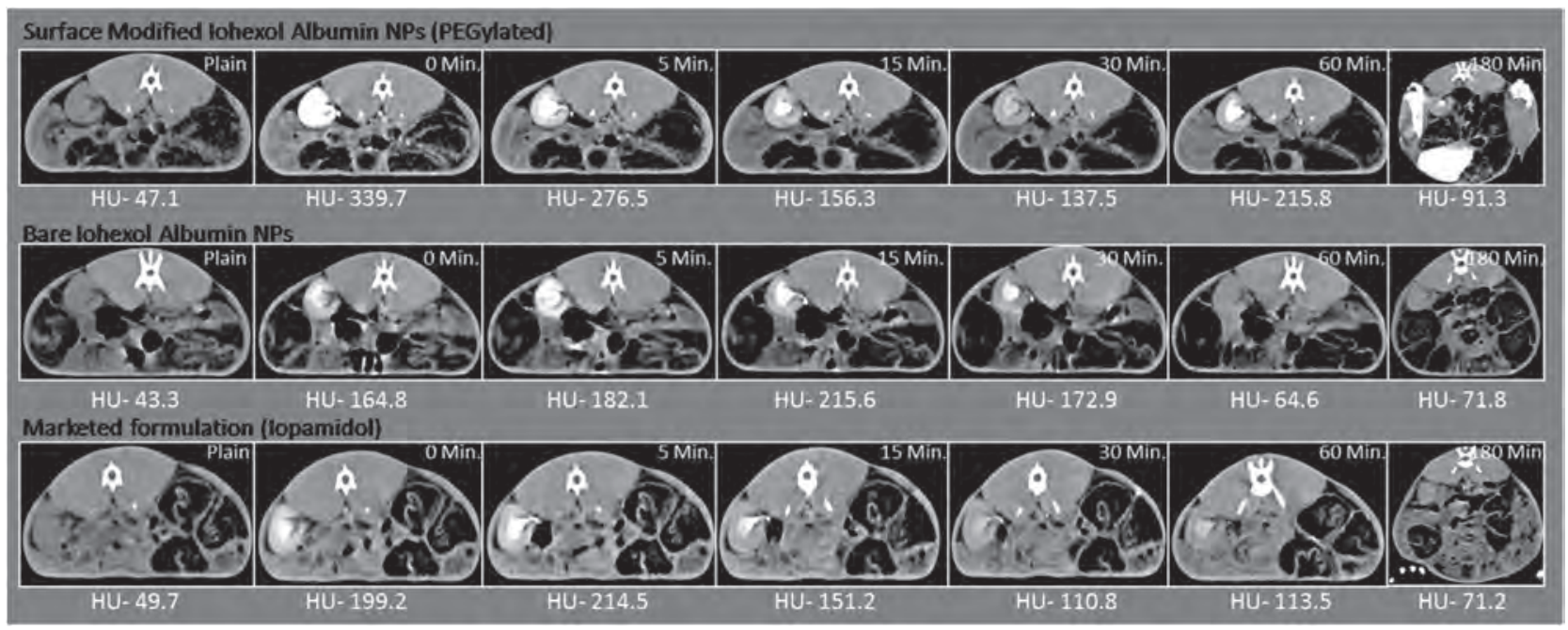

Figure 12. Representative computed tomographic axial images of rabbit demonstrating contrast visualization and variation in HU values of kidney cortex and medulla acquired at various time points such as precontrast, 0, 5, 15, 30, 60 and 180 minutes after injection of three different contrast agent formulations. 

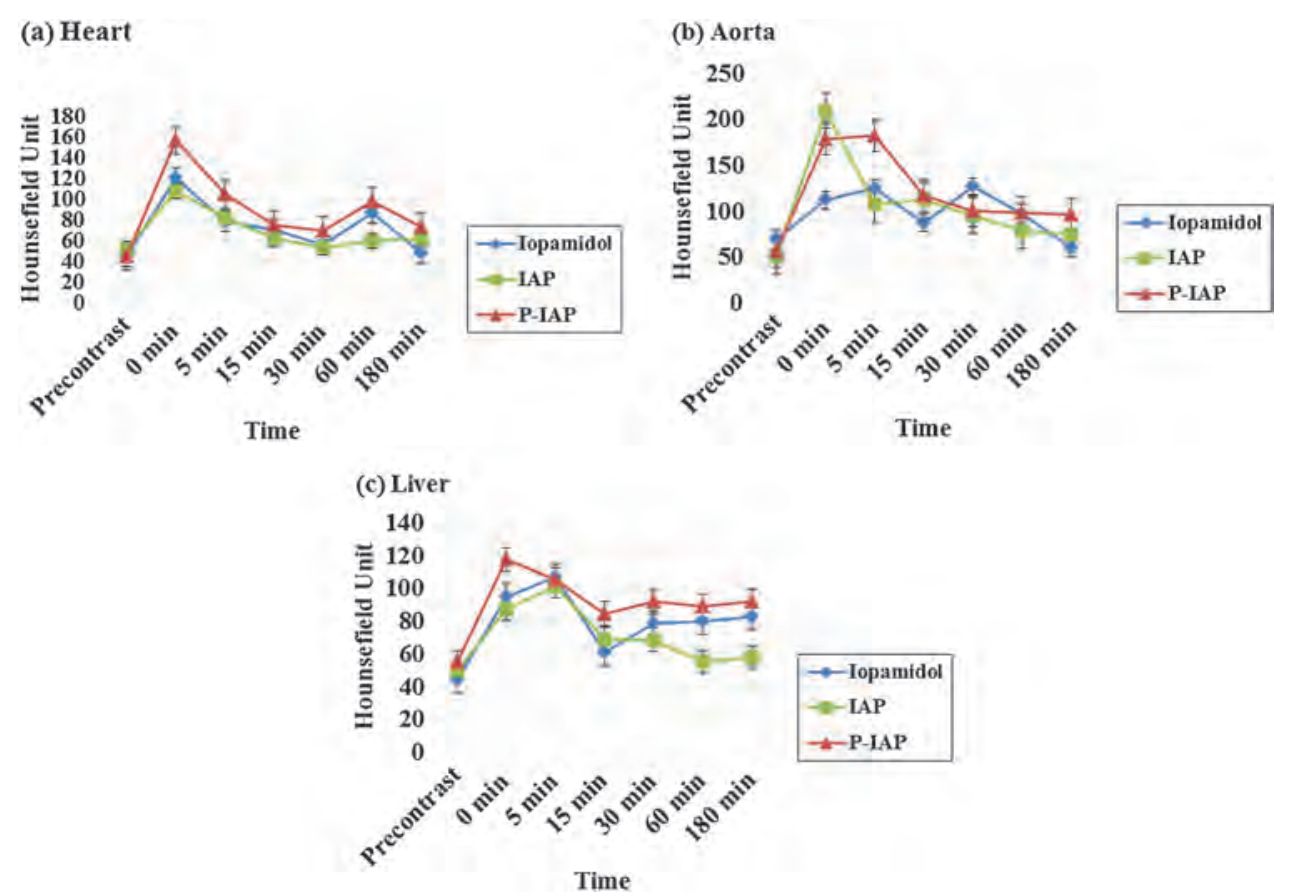

Figure 13. CT enhancement in (a) heart (b) aorta and (c) liver after intravenous administration of lopamidol, IAP and P-IAP.

acculturated as CT contrast media. ${ }^{14}$ Nanoparticles made of natural and hydrophilic polymers, including proteins such as gelatin, collagen, and albumin have been studied to be efficient drug carriers and are evaded by the reticuloendothelial system. ${ }^{39}$ Albumin in particular has been vastly explored among potential drug carrier system which alleviates its stability not only during storage but also in the systemic circulation. Albumin based nanoparticles are studied to be non-toxic, non-antigenic and feasible to scale up over other conventional drug delivery systems. ${ }^{40-43}$ Based on these findings, our study formulated protein based contrast media for CT. The synthesized IAP showed excellent stability with a narrow size range and efficient loading efficiency of Iohexol. The formulated contrast media showed efficient solubility and sustained release of Iohexol. These criteria marked the probable increased in $t_{1 / 2}$ in vivo. Our study is in concordance with earlier reports where, albumin based nanoparticles loaded with anti-cancer drug with a size ranging between 100 and $150 \mathrm{~nm}$ were effective as targeted therapy for breast cancers. $^{44-46}$

The size of the nanoformulation prepared by desolvation technique of synthesizing IAP is monitored by desolvating agent, $\mathrm{pH}$ and not the cross linker. ${ }^{42,47}$ This study was concordat with our results, showing an apt and stable formulation at a concentration of $25 \mu \mathrm{L} / \mathrm{mL}$ of glutaraldehyde, but variation with stability was affected by varying stirring time.

Albumin is also well known for its efficacious drug loading capacity due to the presence of various drug binding sites like Suldow's site. ${ }^{48-51}$ In agreement to the aforementioned fact our study also determined potent entrapment of iophexol. This hypothesis is supported by a study by Zaho et al., where a hydrophobic drug paclitaxil was loaded into albumin forming nanocomposite, with an entrapment efficiency of $95.3 \% .^{52}$ This mechanism
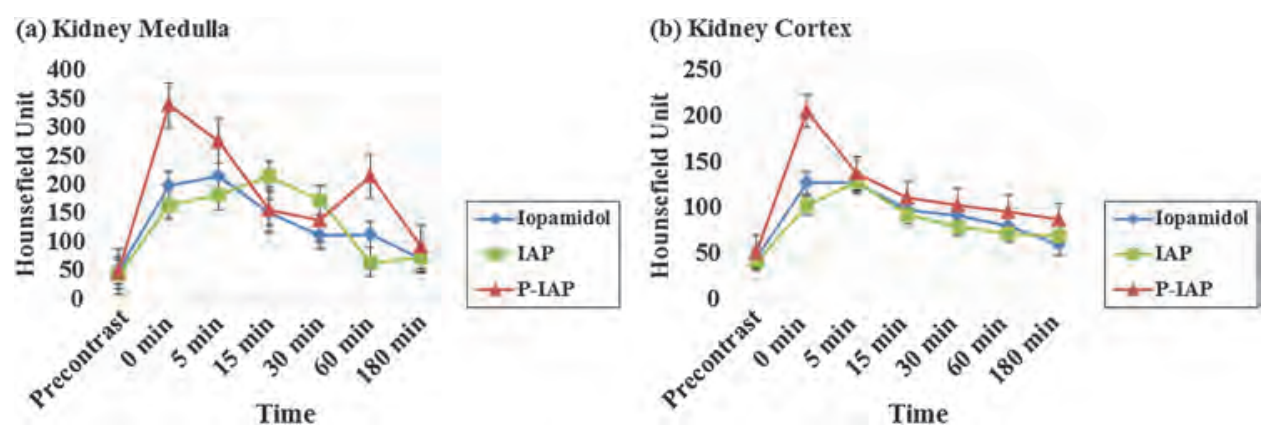

Figure 14. CT enhancement in (a) kidney medulla and (b) kidney cortex after intravenous administration of lopamidol, IAP and P-IAP. 
of association of drug or contrast agent to the binding site of albumin might be due to electrostatic adsorption of charged molecules towards the content of charged amino acids in the primary structure of albumin. ${ }^{47,53}$

Due to define primary structure of albumin, it propounds diverse prospects for surface modifications due to the amino and carboxyl groups. ${ }^{47,54,55}$ Surface modification can be brought about by the formation of covalent bond between the available functional groups and desired ligands. On the contrary, surface modification by electrostatic adsorption techniques are also utilized. In such a combination of protein (albumin) and a ligand, albumin operates as a nanosystem carrier, while the ligand plays a paramount role in augmenting the pharmacokinetic parameters such as stability and increased shelf life in blood pool. ${ }^{30}$ We adapted the electrostatic surface adsorption technique to modify the surface of IAP using PEG and thus producing the surface modified P-IAP. PEGylation of nanocomposite structures for in vivo application is done to enhance the circulation time of the nanocomposite which embeds drug or contrast agent by fifty folds, while reducing their immunogenicity. ${ }^{56}$ In accordance to the hypothesis of PEGylation, our study showed an efficient retention of the surface modified P-IAP in circulation, showing enhanced anatomical structures in vivo. Further, studies showed a slow release of 5-fluorouracil and Rose Bengal from PEGylated albumin nanoparticles. ${ }^{57,58}$

Synthesized IAP and P-IAP were studied to be highly stable in aqueous suspension with least clogging and excellent syringebility. Studies show that Human serum albumin based nanoparticles are stable in suspension at $4{ }^{\circ} \mathrm{C}$ for a period of 6 months, and lyophilization extended their shelf life, where $5 \%$ glucose was used as a stabilizer. ${ }^{59-61}$ In contrast to this study, our study showed an increase in the particle size of the lyophilized IAP and P-IAP, though highly stable. Mannitol, glucose sucrose are generally used as cryoprotectants in terms of long term storage, simultaneously preventing aggregation of albumin based nanocomposite structures. ${ }^{59}$

Our study focused on increasing the residence time of contrast in the blood pool by surface modification of IAP by creating sterically stabilized NPs. The ideal system for delivery of long circulating contrast agents should have minimal agent release in vivo which will allow prolonged imaging studies and repeated scans in CT. Both in vitro and in vivo studies showed slow release of iohexol from the surface modified nanoparticle formulation as compared to bare nanoparticle formulation which, might be due to existence of a steric hydrophilic barrier on the surface of the NPs which made digestion of the NPs more difficult. ${ }^{57}$ It is known that extracellular agents with small molecular weights such as iohexol have much faster clearance profile in vivo compared to colloidal carriers such as liposome's. ${ }^{62}$ Therefore, as the encapsulated agents are released from the liposomes, the signal enhancement diminishes in CT at a rate that is proportional to that of agent release and clearance.

Visualization of organs like heart and kidneys were more distinct after injection of PEGylated nanoparti-cle formulation as compared to the other formulations. Liver enhancement was substantially lower than vascular enhancement but remained relatively stable over $180 \mathrm{~min}$; this indicates that modification via PEGylation decreases first-pass extraction and increase NPs serum half-life. Although uptake of NP's from the blood to the liver may occur relatively quickly, hepatic processing and biliary excretion of these particles is relatively slow, resulting in prolonged retention within the liver parenchyma itself. ${ }^{63}$ Long circulation of drugs in the body is the key to successful drug delivery and drug targeting to the site of action. ${ }^{64}$ In our study PEGylation of iohexol albumin NPs was useful in achieving these goals by improving the residence time of contrast agent in the organs and showed stable enhancement of the intravascular space for more than $3 \mathrm{~h}$. similar results were earlier reported [65].

\section{CONCLUSION}

Our study showed an efficiently entrapped iohexol in IAP and P-IAP nanoformulation, with enhanced residence time and produced stable and high opacification of the blood pool than the marketed Iopamidol producing much greater conspicuity of anatomic features and can be utilized in CT imaging and organ visualization. P-IAP showed remarkable stability, slow release and prolongs retention in different organs which made it possible to acquire CT images over wide time frame without multiple administration and can improve diagnostic accuracy for representation of the region of interest. Applications of such nanoparticle formulations will open new avenues for the procedures which require longitudinal and repeated imaging such as image-guided surgical interventions. However, improvement in surface modification using functionalized PEG and mod-ifying the surface by formation covalent bonds might improve the efficacy of IAP. Further to assure the safety of such diagnostic tools, a detailed toxicity and pharma-cokinetic profile would give better insights to carry for-ward to clinics. Although many important goals have been achieved in terms of stabilization and longer time of con-trast agents in circulation, more investigations are needed to study these formulations in diseased animals and clini-cal conditions.

\section{REFERENCES}

1. B. L. McClennan and M. Perston, Hickey memorial lecture, Ionic and nonionic iodinated contrast media: Evolution and stratergies for use AJR. Am. J. Roentgenol. 155, 225 (1990).

2. S. B. Yu and A. D. Watson, Metal-based X-ray contrast media. Chem. Rev. 99, 2353 (1999). 
3. J. M. Widmark, Imaging related medications: A class overview, Pro. Baylor Med. Cen. Pharmacol. Notes: Garland 20, 408 (2007).

4. V. Engelbrecht, J. Koch, M. Rassek, and U. Mödder, Gadodiamide and gadolinium-DTPA as intravenous media in computed tomography. Rofo. 165, 24 (1996).

5. S. B. Yu, M. Droege, B. Segal, S.-H. Kim, T. Sanderson, and A. D. Watson, Cuboidal W3S4 cluster complexes as new generation X-ray contrast agents. Inorg. Chem. 39, 1325 (2000).

6. M. Frank-Kamenetsky, A. Grefhorst, N. N. Anderson, T. S. Racie, B. Bramlage, A. Akinc, D. Butler, K. Charisse, R. Dorkin, and Y. Fan, Therapeutic RNAi targeting PCSK9 acutely lowers plasma cholesterol in rodents and LDL cholesterol in nonhuman primates. Proceedings of the National Academy of Sciences, USA 105, 11915 (2008)

7. D. Peer, J. M. Karp, S. Hong, O. C. Farokhzad, R. Margalit, and R. Langer, Nanocarriers as an emerging platform for cancer therapy. Nat. Nanotechnol. 2, 751 (2007).

8. G. von Maltzahn, J.-H. Park, A. Agrawal, N. K. Bandaru, S. K. Das, M. J. Sailor, and S. N. Bhatia, Computationally guided photothermal tumor therapy using long-circulating gold nanorod antennas. Cancer Res. 69, 3892 (2009).

9. D. Kim, S. Park, J. H. Lee, Y. Y. Jeong, and S. Jon, Antibiofouling polymer-coated gold nanoparticles as a contrast agent for in vivo X-ray computed tomography imaging. J. Am. Chem. Soc. 129, 7661 (2007)

10. V. J. Caride H. D. Sostman, J. Twickler, H. Zacharias, S. C. Orphanoudakis, and C. C. Jaffe, Brominated radiopaque liposomes: Contrast agent for computed tomography of liver and spleen: A preliminary report. Invest. Radiol. 17, 381 (1982).

11. S. W. Chou, Y. H. Shau, P. C. Wu, Y. S. Yang, D. B. Shieh, and C. C. Chen, In vitro and in vivo studies of FePt nanoparticles for dual modal CT/MRI molecular imaging. J. Am. Chem. Soc. 132, 13270 (2010)

12. O. Rabin, J. M. Perez, J. Grimm, G. Wojtkiewicz, and R. Weissleder, An X-ray computed tomography imaging agent based on longcirculating bismuth sulphide nanoparticles. Nat. Mater. 5, 118 (2006)

13. A. T. Yordanov, A. L. Lodder, E. K. Woller, M. J. Cloninger, N. Patronas, D. Milenic, and M. W. Brechbiel, Novel iodinated dendritic nanoparticles for computed tomography (CT) imaging. Nano Lett. 2, 595 (2002).

14. D. P. Cormode, P. C. Naha, and Z. A. Fayad, Nanoparticle contrast agents for computed tomography: A focus on micelles. Contrast Media Mol. Imaging 9, 37 (2014).

15. F. Stacul, A. J. van der Molen, P. Reimer, J. A. Webb, H. S. Thomsen, S. K. Morcos, T. Almén, P. Aspelin, M.-F. Bellin, and O. Clement, Contrast induced nephropathy: Updated ESUR contrast media safety committee guidelines. Eur. Radiol. 21, 2527 (2011).

16. T. S. Desser, D. L. Rubin, H. Muller, G. L. McIntire, E. R. Bacon, and J. L. Toner, Blood pool and liver enhancement in CT with liposomal lodixanol: Comparison with lohexol. Acad. Radiol. 6, 176 (1999).

17. X. Montet, C. M. Pastor, J.-P. Vallée, C. D. Becker, A. Geissbuhler, D. R. Morel, and P. Meda, Improved visualization of vessels and hepatic tumors by micro-computed tomography (CT) using iodinated liposomes. Invest. Radiol. 42, 652 (2007).

18. S. Mukundan Jr., K. B. Ghaghada, C. T. Badea, C.-Y. Kao, L. W. Hedlund, J. M. Provenzale, G. A. Johnson, E. Chen, R. V. Bellamkonda, and A. Annapragada, Liposomal contrast agent for preclinical CT in mice. Am. J. Roentgenol. 186, 300 (2006).

19. V. Mohanraj and Y. Chen, Nanoparticles-A review. Trop. J. Pharma. Res. 5, 561 (2007).

20. Y. Li, M. Ogris, E. Wagner, J. Pelisek, and M. Rüffer, Nanoparticles bearing polyethyleneglycol-coupled transferrin as gene carriers: Preparation and in vitro evaluation. Int. J. Pharm. 259, 93 (2003).
21. C. Perez, A. Sanchez, D. Putnam, D. Ting, R. Langer, and M. Alonso, Poly(lactic acid)-poly(ethylene glycol) nanoparticles as new carriers for the delivery of plasmid DNA, J. Control. Release. 75, 211 (2001).

22. S. K. Sahoo and V. Labhasetwar, Nanotech approaches to drug delivery and imaging, Drug Discov. 8, 1112 (2003).

23. H. Aviv, S. Bartling, F. Kieslling, and S. Margel, Radiopaque iodinated copolymeric nanoparticles for X-ray imaging applications. Biomaterials 30, 5610 (2009).

24. W. H. Kong, W. J. Lee, Z. Y. Cui, K. H. Bae, T. G. Park, J. H. Kim, K. Park, and S. W. Seo, Nanoparticulate carrier containing water-insoluble iodinated oil as a multifunctional contrast agent for computed tomography imaging. Biomaterials 28, 5555 (2007)

25. D. B. Elrod, R. Partha, D. Danila, S. W. Casscells, and J. L. Conyers, An iodinated liposomal computed tomographic contrast agent prepared from a diiodophosphatidylcholine lipid. Nanomedicine 5, 42 (2009).

26. M. Rahimnejad, M. Jahanshahi, and G. H. M. M. Najafpour, Fabrication of bovine serum albumin nanoparticles self-assembled coacervation method for drug delivery systems. J. Tech. Engine. 4, 26 (2006)

27. M. C. Roco, Nanotechnology: Convergence with modern biology and medicine. Curr. Opin. Biotechnol. 14, 337 (2003).

28. S. S. Suri, H. Fenniri, and B. Singh, Nanotechnology-based drug delivery systems. J. Occup. Med. Toxicol. 2, 16 (2007).

29. V. Torchilin, Nanotechnology in Drugs, Imperial College Press, London (2008).

30. A. O. Elzoghby, W. M. Samy, and N. A. Elgindy, Albumin-based nanoparticles as potential controlled release drug delivery systems. J. Control. Release 157, 168 (2012).

31. M. Ghosh, Indian Journal of Pharmacology 39, 216 (2007)

32. H. Katayama, K. Yamaguchi, T. Kozuka, T. Takashima, P. Seez, and $\mathrm{K}$. Matsuura, Adverse reactions to ionic and nonionic contrast media, a report from the Japanese committee on the safety of contrast media. Radiology 175, 621 (1990).

33. W. H. Shehadi, Adverse reactions to intravascularly administered contrast media, a comprehensive study based on a prospective survey. Am. J. Roentgenol. Radium. Ther. Nucl. Med. 124, 145 (1975).

34. R. W. Katzberg, Urography into the 21 st century: New contrast media, renal handling, imaging characteristics, and nephrotoxicity. Radiology 204, 297 (1997).

35. D. A. Baumgarten and J. H. Ellis, Contrast-induced nephropathy: Contrast material not required? AJR Am. J. Roentgenol. 191, 383 (2008).

36. Q. A. Rao and J. H. Newhouse, Risk of nephropathy after intravenous administration of contrast material: A critical literature analysis. Radiology 239, 392 (2006).

37. K. L. Grant and J. M. Camamo, Adverse events and cost savings three years after implementation of guidelines for outpatient contrast-agent use. Am. J. Health Syst. Pharm. 54, 1395 (1997).

38. M. Shilo, T. Reuveni, M. Motiei, and R. Popovtzer, Nanoparticles as computed tomography contrast agents-current status and future perspectives. Nanomedicine 7, 257 (2012).

39. Z. Liu, Y. Jiao, Y. Wang, C. Zhou, and Z. Zhang, Polysaccharidesbased nanoparticles as drug delivery systems. Adv. Drug Deliv. Rev. 60, 1650 (2008)

40. S. Azarmi, X. Tao, H. Chen, Z. Wang, W. H. Finlay, R. Löbenberg, and W. H. Roa, Formulation and cytotoxicity of doxorubicin nanoparticles carried by dry powder aerosol particles. Int. J. Pharm. 319, 155 (2006)

41. S. Kommareddy and M. Amiji, Preparation and evaluation of thiolmodified gelatin nanoparticles for intracellular DNA delivery in response to glutathione. Bioconjug. Chem. 16, 1423 (2005).

42. K. Langer, S. Balthasar, V. Vogel, N. Dinauer, H. Von Briesen, and D. Schubert, Optimization of the preparation process for human serum albumin (HSA) nanoparticles. Int. J. Pharm. 257, 169 (2003). 
43. O. P. Rubino, R. Kowalsky, and J. Swarbrick, Albumin microspheres as a drug delivery system: Relation among turbidity ratio, degree of cross-linking and drug release. Pharm. Res. 10, 1059 (1993).

44. J. Cortes and C. Saura, Nanoparticle albumin-bound $\left(\mathrm{nab}^{\mathrm{TM}}\right)$ paclitaxel: Improving efficacy and tolerability by targeted drug delivery in metastatic breast cancer. EJC Suppl. 8, 1 (2010).

45. N. Desai, Abraxis BioScience, Inc. Nanoparticle albumin bound (nab) technology: Targeting tumors through the endothelial gp60 receptor and SPARC. Nanomedicine 3, 337 (2007).

46. T. H. Kim, H. H. Jiang, Y. S. Youn, C. W. Park, K. K. Tak, S. Lee, H. Kim, S. Jon, X. Chen, and K. C. Lee, Preparation and characterization of water-soluble albumin-bound curcumin nanoparticles with improved antitumor activity. Int. J. Pharm. 403, 285 (2011).

47. C. Weber, C. Coester, J. Kreuter, and K. Langer, Desolvation process and surface characteristics of protein nanoparticles. Int. J. Pharm. 194, 91 (2000).

48. M. Fasano, S. Curry, E. Terreno, M. Galliano, G. Fanali, P. Narciso, S. Notari, and P. Ascenzi, The extraordinary ligand binding properties of human serum albumin. IUBMB Life 57, 787 (2005).

49. G. V. Patil, Biopolymer albumin for diagnosis and in drug delivery, Drug Dev. Res. 58, 219 (2003).

50. G. Sudlow, D. Birkett, and D. Wade, The characterization of two specific drug binding sites on human serum albumin. Mol. Pharmacol. 11, 824 (1975).

51. H. Tajmir-Riahi, An overview of drug binding to human serum albumin: Protein folding and unfolding, Sci. Iran. 14, 87 (2007).

52. D. Zhao, X. Zhao, Y. Zu, J. Li, Y. Zhang, R. Jiang, and Z. Zhang, Preparation, characterization, and in vitro targeted delivery of folatedecorated paclitaxel loaded bovine serum albumin nanoparticles. Int. J. Nanomedicine 5, 669 (2010).

53. J. Irache, M. Merodio, A. Arnedo, M. Camapanero, M. Mirshahi, and S. Espuelas, Albumin nanoparticles for the intravitreal delivery of anticytomegaloviral drugs. Mini Rev. Med. Chem. 5, 293 (2005).

54. I. M. Steinhauser, K. Langer, K. M. Strebhardt, and B. Spänkuch, Effect of trastuzumab-modified antisense oligonucleotide-loaded human serum albumin nanoparticles prepared by heat denaturation. Biomaterials 29, 4022 (2008).
55. K. Ulbrich, T. Hekmatara, E. Herbert, and J. Kreuter, Transferrinand transferrin-receptor-antibody-modified nanoparticles enable drug delivery across the blood-brain barrier (BBB). Eur. J. Pharm. Biopharm. 71, 251 (2009).

56. H. Kouchakzadeh, S. A. Shojaosadati, A. Maghsoudi, and E. V. Farahani, Optimization of PEGylation conditions for BSA nanoparticles using response surface methodology. AAPS Pharm. Sci. Tech. 11, 1206 (2010).

57. W. Lin, M. C. Garnett, S. S. Davis, E. Schacht, P. Ferruti, and L. Illum, Preparation and characterization of Rose Bengal-loaded surface-modified albumin nanoparticles. J. Control. Release 71, 117 (2001).

58. K. Santhi, S. Dhanaraj, V. Joseph, S. Ponnusankar, and B. Suresh, A study on the preparation and anti-tumor efficacy of bovine serum albumin nanospheres containing 5-fluorouracil. Drug Dev. Ind. Pharm. 28, 1171 (2002).

59. P. V. Kumar and N. K. Jain, Suppression of agglomeration of ciprofloxacin-loaded human serum albumin nanoparticles. AAPS Pharm. Sci. Tech. 8, E118 (2007).

60. S. H. Lee, D. Heng, W. K. Ng, H.-K. Chan, and R. B. Tan, Nano spray drying: A novel method for preparing protein nanoparticles for protein therapy. Int. J. Pharm. 403, 192 (2011).

61. S. Yu, P. Yao, M. Jiang, and G. Zhang, Nanogels prepared by self-assembly of oppositely charged globular proteins. Biopolymers 83, 148 (2006).

62. M. Saeed, M. F. Wendland, and C. B. Higgins, Blood pool MR contrast agents for cardiovascular imaging. J. Magn. Reson. Imaging 12, 890 (2000).

63. H. S. Choi, W. Liu, P. Misra, E. Tanaka, J. P. Zimmer, B. I. Ipe, M. G. Bawendi, and J. V. Frangioni, Renal clearance of quantum dots. Nat. Biotechnol. 25, 1165 (2007).

64. K. S. Soppimath, T. M. Aminabhavi, A. R. Kulkarni, and W. E. Rudzinski, Biodegradable polymeric nanoparticles as drug delivery devices. J. Control. Release 70, 1 (2001).

65. C. Y. Kao, E. A. Hoffman, K. C. Beck, R. V. Bellamkonda, and A. V. Annapragada, Long-residence-time nano-scale liposomal iohexol for X-ray-based blood pool imaging, Acad. Radiol. 10, 475 (2003). 